\title{
Electron Capture Dissociation Distinguishes a Single D-Amino Acid in a Protein and Probes the Tertiary Structure
}

\author{
Christopher M. Adams, Frank Kjeldsen, ${ }^{*}$ and Roman A. Zubarev \\ Laboratory for Biological and Medical Mass Spectrometry, Uppsala University, Uppsala, Sweden
}

\author{
Bogdan A. Budnik ${ }^{+}$and Kim F. Haselmann \\ Department of Chemistry, University of Southern Denmark, Odense, Denmark
}

\begin{abstract}
First results are reported on the application of ECD in analysis of $2+$ and $3+$ ions of stereoisomers of Trp-cage (NLYIQWLKDGGPSSGRPPPS), the smallest and fastest-folding protein, which exhibits a tightly folded tertiary structure in solution. The chiral recognition based on the ratios of the abundances of $z_{18}$ and $z_{19}$ fragments in ECD of $2+$ ions was excellent even for a single amino acid $(\mathrm{Tyr}) \mathrm{D}$-substitution $\left(R_{\text {chiral }}=8.6\right)$. The chiral effect decreased with an increase of temperature at the electrospray ion source, as well as at a higher degree of ionization, $3+$ ions $\left(R_{\text {chiral }}=1.5\right)$. A general approach is suggested for charge localization in $n+$ ions by analysis of ECD mass spectra of $(n+1)+$ ions. Application of this approach to $3+$ Trp-cage ions revealed the protonation probability order in $2+$ ions: $\operatorname{Arg}_{16} \gg \operatorname{Gln}_{5}>\approx$ $\mathrm{N}$-terminus. The ECD results for native form of the 2+ ions favor the preservation of the solution-phase tertiary structure, and chiral recognition through the interaction between the charges and the neutral bond network. Conversely, ECD of $3+$ ions supports the dominance of ionic hydrogen bonding which determines a different gas-phase structure than found in solution. Vibrational activation of $2+$ ions indicated greater stability of the native form, but the fragmentation patterns did not provide stereoisomer differentiation, thus underlying the special position of ECD among other MS/MS fragmentation techniques. Further ECD studies should yield more structural information as well as quantitative single-amino acid D/L content measurements in proteins. (J Am Soc Mass Spectrom 2004, 15, 1087-1098) (C) 2004 American Society for Mass Spectrometry
\end{abstract}

A $\mathrm{s}$ mass spectrometry continues to advance in elucidating structures of biomolecules, the issue of the "memory" retained by the molecule in the transition from the solution phase to the gas phase remains widely debated. Electrospray ionization (ESI) acts as the mediator in such transition for protein molecules [1]. For years, biochemists have known the importance of $\mathrm{pH}$, solvent, and temperature in influencing protein structure in solution [2-5]. ESI is widely considered a "soft" ionization technique allowing, under certain experimental conditions, conformational

Published online June 10, 2004

Address reprint requests to Dr. R. A. Zubarev, Laboratory for Biological and Medical Mass Spectrometry, Uppsala Biomedical Centrum, Uppsala University, Box 583, Uppsala 75 123, Sweden. E-mail: roman.zubarev@ bmms.uu.se

*Also at the Department of Chemistry, University of Southern Denmark, Odense, Denmark.

${ }^{+}$Current address: Department of Biochemistry, Boston University, Boston, MA, USA.

Supplementary material available: Rotating 3-D model of the Trp-cage molecule (PowerPoint). differences to be explored in the gas phase [6-8]. It has been repeatedly shown that non-covalent complexes can retain memory of their solution phase assemblies after ESI [9-12]. Furthermore, charge state distribution of many proteins is largely directed by solvent composition and $\mathrm{pH}$, consistent with different protein conformations in the gas phase [13-15]. The electrospray source conditions can also influence the conformational distribution of the protein ions. These parameters include capillary temperature, source pressure and voltage $[7,8]$.

Various mass analysis techniques have been employed in understanding protein ion conformations in vacuo, and in particular that of Fourier transform ion cyclotron resonance mass spectrometry (FTICR MS). As FTICR MS has the advantages of high mass resolution and the ability to trap ions for extended time periods (minutes), it is a convenient platform for a multitude of gas-phase ion reactions, including electron capture dissociation (ECD). To date, some of the techniques used to probe gas-phase structures of biomolecules include gas- 
and solution-phase hydrogen-deuterium exchange [16, 17], gas-phase ion mobility [18], proton transfer reactivity experiments [19], and the secondary mass spectrometry (MS/MS) techniques of collisionally activated dissociation (CAD) [20, 21], infrared multiphoton dissociation (IRMPD) [22] , ECD [23, 24], as well as kinetic energy release [25].

The ECD technique stands alone among MS/MS techniques, as $\mathrm{N}-\mathrm{C}_{\alpha}$ backbone cleavage can occur without rupture of weak intra- and inter- molecular bonding [26]. McLafferty et al. have employed ECD as a probe for the secondary and tertiary gas-phase structures of ubiquitin and cytochrome $c$ [27-29]. In short, $\mathrm{N}-\mathrm{C}_{\alpha}$ bond cleavage occurs near the carbonyl oxygen participating in charge solvation (e.g., $-\mathrm{NH}_{3}^{+} \ldots \mathrm{O}=\mathrm{C}$ ). Such participation is hindered if this site is involved in neutral hydrogen bonding (e.g., N. ..H. . O =C). Thus structures with extensive neutral hydrogen bonding produce far less $\mathrm{N}-\mathrm{C}_{\alpha}$ cleavages than fully unfolded structures, and the number of such cleavages can be used as a measure of the degree of protein folding in the gas phase [26-28].

Another ECD feature that can potentially be used for structural studies is the $c, z$ fragment abundances. For polypeptides without neutral hydrogen bonding, these are shown to be both repeatable and reproducible quantities [30]. ECD fragment abundances are determined by local sequence in a much higher degree than CAD and IRMPD abundances [30]. Yet another relevant feature of ECD is the presence of the so-called $(\mathrm{M} \cdot \mathrm{X})$ region, i.e., the region of an ECD mass spectrum immediately below the peak of the reduced species. The $(\mathrm{M}-\mathrm{X})$ region is shown to provide information on the protonation and charge solvation sites [31-33].

The secondary and tertiary structures in gas-phase molecular ions are held together by ionic bonding (imposed by extra protons) and neutral hydrogen bonding. Ionic bonding is by 8 to $30 \mathrm{kcal} / \mathrm{mol}$ per bond stronger than neutral bonding [34], and thus ionic bonding dominates in the gas-phase molecular ions when the number of charges exceeds a critical value. McLafferty et al. found $\alpha$-helicity induced by extensive protonation in gaseous 13+ of ubiquitin [27]. Even the $6+$ charge state of ubiquitin was found to have a proton-bound structure significantly different from that in solution $[27,28]$. Yet, below critical charging, neutral hydrogen bonding should prevail and thus solutionphase structure may be preserved in the gas phase. The question that we address in this study is to what extent ECD mass spectra of lowly-charged proteins can be correlated with neutral hydrogen-bonded structures found in solutions. The low charge state requirement poses a dilemma, as FTICR MS rapidly loses mass resolution as $\mathrm{m} / \mathrm{z}$ increases. The majority of ECD fragments have a higher $\mathrm{m} / \mathrm{z}$ than precursor ions, which exacerbates the problem. Thus, the model protein should be small yet with a distinct tertiary structure in solution.

The model system NLYIQWLKDGGPSSGRPPPS chosen for this study is better known as the "Trp-cage" motif. At twenty amino acids and MW 2168, the Trpcage is the smallest known protein defined by tertiary structure [35]. It has acted as a model in real time kinetics experiments and in computational folding studies [36-40]. In the solution phase, Trp-cage is dominated by a hydrophobic core, consisting of a tryptophan residue stabilized by three proline residues and one tyrosine [41]. The NMR data showed that the hydrophobic region is packed against the N-terminal $\alpha$-helix and a short $3_{10}$-helix [35]. Extensive hydrogen bonding also plays a critical role in solution phase stability, particularly in the $\alpha$-helix region. The Trpsidechain $\mathrm{NH} \varepsilon 1$ has also been reported as being actively involved in hydrogen bonding to the Arg backbone carbonyl [41]. The NMR data showed enhanced Trp-cage solution phase stability in 30\% TFE compared with $\mathrm{pH} 7$ water [35], raising hope that the solutionphase structure could be preserved in the gas-phase.

As a probing tool for the ability of ECD to detect structural changes, we chose D-amino acid substitution, a well-known technique for destabilizing solutionphase secondary and tertirary structure, especially that of $\alpha$-helices [42, 43]. At the same time, most other physico-chemical properties, including the molecular mass and masses of fragments, are preserved upon such substitution, unlike in substitution by another aminoacid. Here we present the first results highlighting the potential of this approach.

\section{Experimental}

\section{Protein Synthesis}

Proteins, including the all-L form which will be called "native", as well as a number of D-substitution variants, were synthesized using solid-phase Fmoc chemistry with an Applied Biosystems 431A (Foster City, CA) and Intavis AG ResPep (Gladbach, Germany) peptide synthesizers. D-isomer amino acids were purchased from Novabiochem (Laufelfingen, Switzerland). Proteins were further purified by reversed phase HPLC using a Vydac C18 column (Hesperia, CA). Final purity was tested by FTICR mass spectrometry.

\section{Mass Spectrometry}

Fourier transform ion cyclotron resonance mass spectrometry was performed in Odense using IonSpec $4.7 \mathrm{~T}$ Ultima and in Uppsala using Bruker 9.4 T Apex II instruments. "Native" sample solution of $10^{-5} \mathrm{M}$ concentration was prepared at $\mathrm{pH} 6.0$ in $10 \mathrm{mM}$ ammonium citrate and used in the Odense experiments. For Uppsala experiments the addition of $10 \%$ methanol was made to the native buffer to assist ESI. "Standard ESI" solution contained water, methanol and acetic acid in proportions 49:49:2 (vol/vol). Proteins were electrosprayed by direct infusion, using capillary voltage 2200 V. Drying gas temperature varied from $25^{\circ} \mathrm{C}$ to $400^{\circ} \mathrm{C}$. 

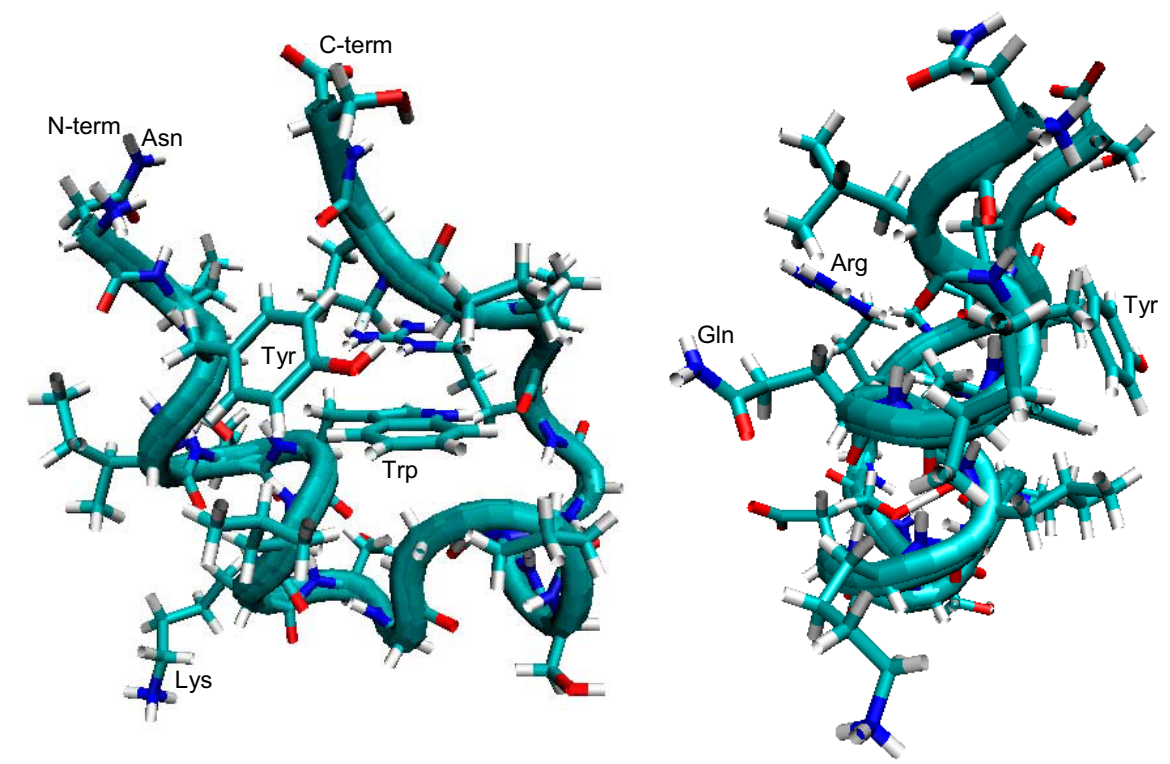

Figure 1. NMR structure of the native form of the Trp-cage protein as viewed with VMD viewer, PDB file 1L2Y [47]. The structure is shown at two different angles differing by ca. $90^{\circ}$.

ECD was performed using an indirectly heated cathode (Heatwave, CA) as previously described [44, 45]. External accumulation in the hexapole, followed by gated trapping (Odense) and side-kick trapping (Uppsala) was used before the desired charge states were selected by application of a stored waveform (Odense).

\section{Results and Discussion}

\section{Solution-Phase Structure and Potential Protonation Sites of the Native Trp-Cage}

Figure 1 presents solution-phase structure of the native Trp-cage obtained by NMR (PDB file 1L2Y.pdb) and viewed with DeepView 3.7 and VMD 1.82 [46, 47].

The protonation sites are important for the gas-phase structure of polypeptide cations, and their determination is not a simple issue. A priori assessment based on gas-phase basicities of free amino acids (Arg $>$ His $>$ Lys $\approx \mathrm{N}$-terminus) singles out the arginine side chain, by far the most basic site, as well as the lysine residue and the $\mathrm{N}$-terminus. However, steric constraints and the possibilities of charge solvation may change gasphase basicities significantly. Coulombic repulsion between charges also changes the apparent basicity of potential protonation sites. For instance, Williams has shown in the point charge model that such parameters as charge separation, vacuum permittivity and charge shielding influence the apparent gas phase basicity of individual amino acids in protein molecules [48]. In any case, as the exothermicity in ECD is falling with increased proton affinity of the neutralized site [49], the most basic site (arginine) is less likely to be attacked by an electron. Thus, C-terminal $z$-fragments of $2+$ Trp- cage are more likely to retain the proton than $\mathrm{N}$ terminal $c$-ions.

\section{Preliminary ECD Data}

ECD of 2+ native Trp-cage was performed in Odense at very mild ESI interface conditions (native solution, low temperature of drying gas, and low nozzle-skimmer voltage). The main feature of the resultant spectrum (Figure 2a) is the absence of backbone fragmentation, except losses of terminal residues $\left(z_{19}^{+*}, y_{19}^{+\prime}\right.$, and $c_{19}^{+\prime}$ fragments). This suggests that no charge solvation occurs on internal backbone carbonyls, which are presumably involved in extensive neutral hydrogen bonding. Alternatively, charge solvation occurs at backbone carbonyls but even after ECD the extensive hydrogen bonding keeps these fragments intact. To contrast this with a much distorted solution-phase structure, the D-KSS variant NLYIQWLKGGPSSSGRPPPS (D-amino acids are in bold) was synthesized. At similar experimental conditions $2+$ ions produced the ECD spectrum in Figure $2 b$, which is dominated by $z$-ions. The $z$ series is consistent with our expectations of an unfolded structure, as well as charge retention on the arginine residue. The $(\mathrm{M} \cdot \mathrm{X})$ regions $(1<\mathrm{X}<80 \mathrm{Da})$ below the reduced species $[\mathrm{M}+2 \mathrm{H}]^{+\cdot}$ were nearly identical in both Figure 2 spectra, suggesting strong similarities in charge locations. These similarities indicated that the observed differences in ECD mass spectra were due to neutral, rather than ionic, hydrogen bonding. The most abundant $z$-ions were due to cleavages in the central part of the molecule, such as the dominant $z_{12}$ fragment with the C-terminal side adjacent to the D-Lys residue. 

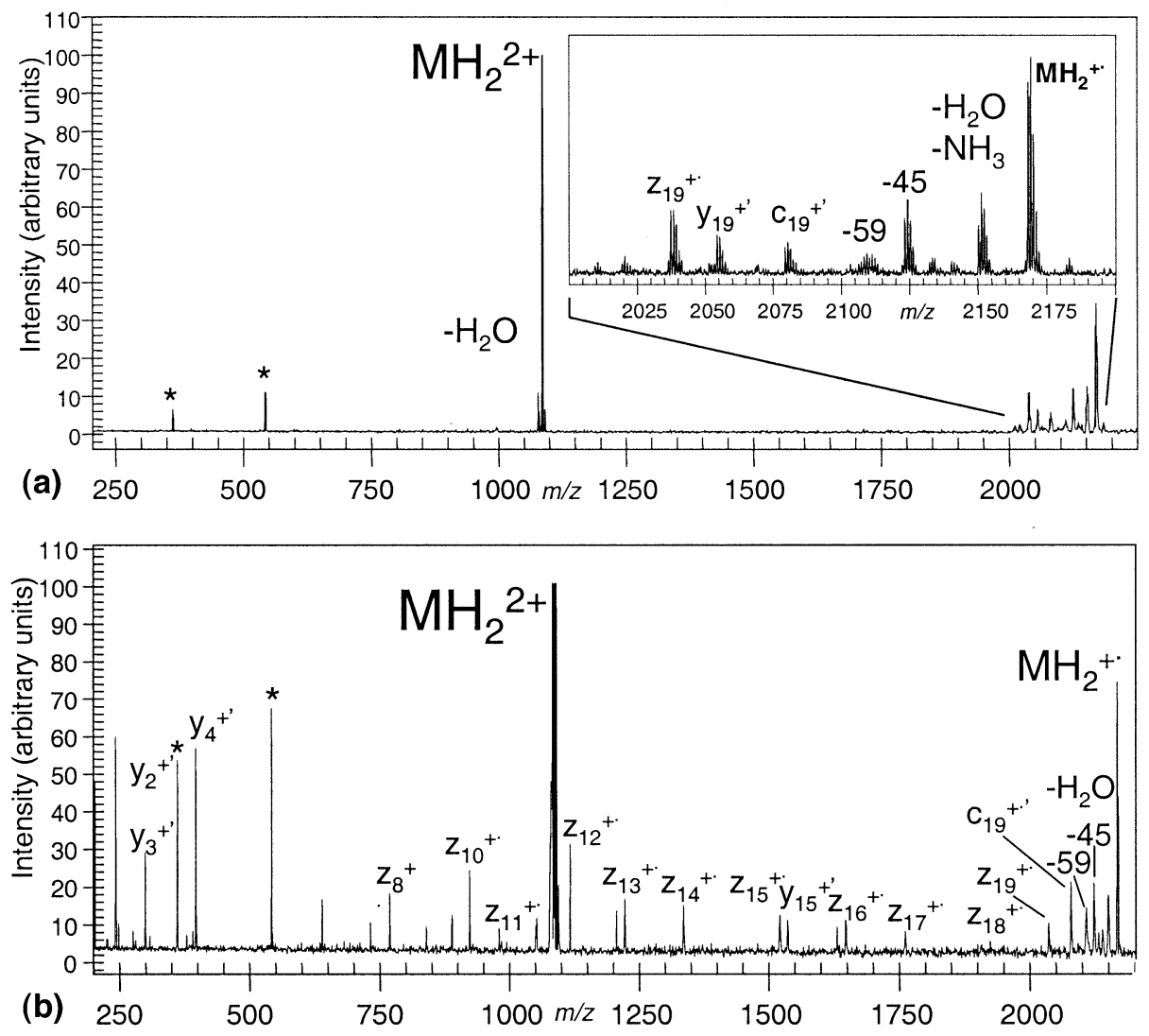

Figure 2. ECD mass spectra of 2+ molecular ions of (a) native Trp-cage; (b) D-KSS substituted Trp-cage, obtained at mild conditions of the ESI interface. The $y$ fragments in the low spectrum are presumably due to unwanted collisional activation during $2+$ ion isolation; the absence of these fragments in the upper spectrum testifies to the higher stability of the native form in the gas phase.

The peaks marked by a star are artifacts due to harmonics.

This clear differentiation of two stereoisomers encouraged further experiments.

To test the CAD ability in distinguishing two stereoisomers, SORI CAD was employed, which produced spectra in Figure 3. Not surprisingly, the most abundant complementary pair of fragments, $b_{9}{ }^{+}, y_{11}{ }^{{ }^{\prime}}$, came from the cleavage after the Asp residue, the preferred fragmentation site in CAD [50]. Product-moment correlation analysis [30] was used to quantify the similarity of the intensities of $b, y$ ions in both CAD spectra. The obtained value $R=0.96$ for $y$ ions made the fragmentation patterns statistically indistinguishable, consistent with destruction of neutral hydrogen bonding and extensive proton scrambling upon vibrational excitation. However, even SORI CAD provided clues for higher stability of the native form compared to Dsubstituted. While experimental conditions in both cases remained analogous, the $2+$ ions of the D-KSS molecule were totally destroyed by excitation (Figure $3 b$ ), while some of the native form survived (Figure 3a).

Repeated experiments showed that the lack of internal backbone cleavage found in ECD of $2+$ for the native form is only observed in a narrow range of experimental parameters. In a more general case, a certain amount of $z$-ions were observed. This was not surprising, given that a significant minority of Trp-cage molecules is partially unfolded in solution at $25^{\circ} \mathrm{C}$ [35]. The observed $z$-ions were due to cleavages not far from the N-terminus, their pattern different, and the abundances lower compared to the D-KSS variant. The presence among native $2+$ molecular ions of partially unfolded species that produced the $z$-series was indispensable for the product-moment correlation analysis. The analysis gave $\mathrm{R}=0.42$ for the native form in comparison with the D-KSS variant, suggesting a poor correlation between fragmentation patterns.

\section{Targeted D-Amino Acid Substitution}

Preliminary experiments in Odense raised hope that ECD of proteins in lower charge states can be a sensitive tool for probing differences in protein conformations. To explore this possibility, it was decided to systematically substitute amino acids in the Trp-cage molecule and to monitor the corresponding changes in ECD mass spectra. This extensive work is currently in progress in Uppsala. Here we are reporting first findings, the most striking of which is the reliable detection of structural changes imposed by a single D-amino acid substitution.

So far, ECD has mainly been used to detect differ- 

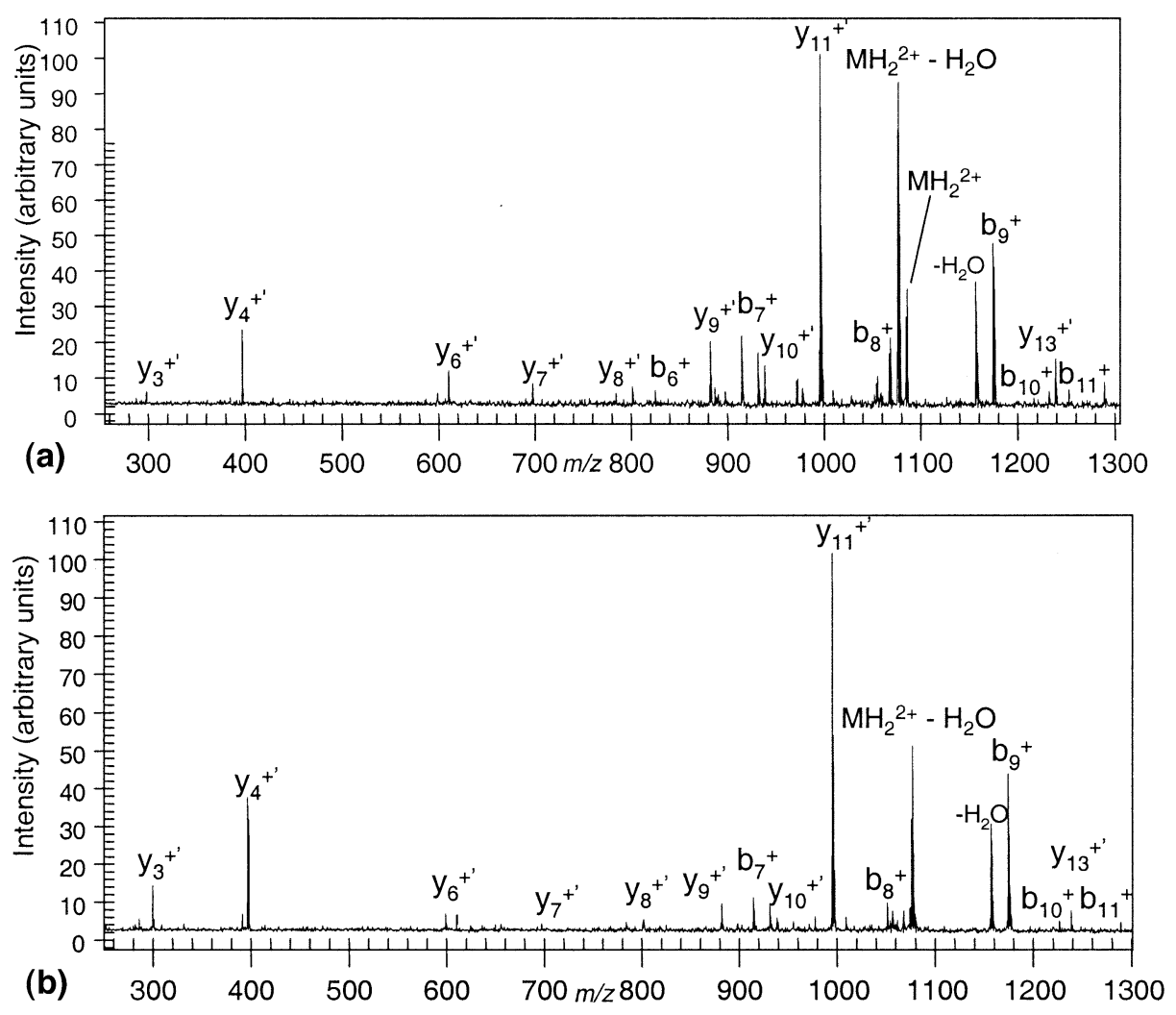

Figure 3. SORI CAD mass spectra of $2+$ molecular ions of (a) native Trp-cage; (b) D-KSS substituted Trp-cage.

ences between constitutional isomers, e.g., between amino acids L-leucine and L-isoleucine [24, 51, 52]. Stereoisomer differentiation by ECD in LHRH with D-substituted Trp residue has been reported [53], but LHRH is too small (10 residues) to form tertiary structure in either solution or the gas phase. The chiral recognition of the $2+$ ions has been observed through the differences in abundances of $z^{\prime}$ versus $z \cdot$ ions, from cleavages adjacent to the substituted residue. With the kinetic method, probably the best documented MS/MS chiral recognition approach, D-amino acid detection in small peptides up to four or five residues long has been possible [54]. In another approach, mass spectrometry coupled with ion mobility spectrometry was capable of distinguishing chiral molecules of similar size [55]. In our case, the single-amino-acid chiral recognition in the 20 residue protein, the largest system so far, is clear from Figure 4. On that figure, the ECD spectrum of 2+ D-Tyr substituted Trp-cage (NLYIQWLKDGGPSSGRP PPS) is shown (Figure 4b) in comparison with that of native Trp-cage (Figure $4 \mathrm{a}$ ).

Correlation analysis $(\mathrm{R}=0.15$, Figure $4 \mathrm{c})$ confirms the significant difference in patterns of the $z$-ions in Figure 4. Mutually, the correlation factor between the native Trp-cage 2+ ECD spectrum in Figure 4a and the one previously obtained in Odense was $\mathrm{R}=0.91$, which corroborates the good reproducibility of the employed analysis technique [30]. In repeated experiments, the average correlation factor between two ECD mass spectra obtained independently on the same instrument at identical instrumental settings was 0.98 .

As a chirality measure $R_{D / L}$ [56], we monitored the ratio of abundances of $z_{18}{ }^{+\cdot}$ and $z_{19}{ }^{+\cdot}$ ions, which was $0.28 \pm 0.02$ for $2+$ of the native form and $2.38 \pm 0.05$ for the D-Tyr form. The degree of chiral distinction, $R_{\text {chiral }}$ $=R_{D} / R_{L}$ [56], was thus $R_{\text {chiral }}=8.55 \pm 0.06$. Such a high value of $R_{\text {chiral }}$ is exceptional even for chiral distinction of free amino acids [56], which raises a hope that the $\mathrm{D} / \mathrm{L}$ ratio in a mixture of native and D-substituted proteins could be quantitatively measured.

Most of the $z$-ions in Figure 4 are radicals, except $z_{13}$ on Figure $4 \mathrm{a}, z_{11}-z_{12}$ in Figure $4 \mathrm{~b}$ and $z_{10}$ in both figures, which carried an extra hydrogen atom. No significant admixture of even-electron species was noticed for the diagnostic $z_{18}$ and $z_{19}$ ions (see inserts in Figure $4 a, b$ ). The chiral distinction, $R_{\text {chiral }}$, was entirely based on $z$-ion abundances, unlike that in 2+ of LHRH [53].

The hydrogen bonding in the native Trp-cage, as well as changes in intensities of $z$-ions after ECD is listed in Table 1. In order to analyze the chiral effect of the Tyr residue on $2+$ ion structure, the knowledge of the location of positive charges is required. As will follow from the analysis of $3+$ data provided, one protonation site is the arginine, while the second proton is distributed between the N-terminus and the glutamine side chain. This protonation pattern is the same 


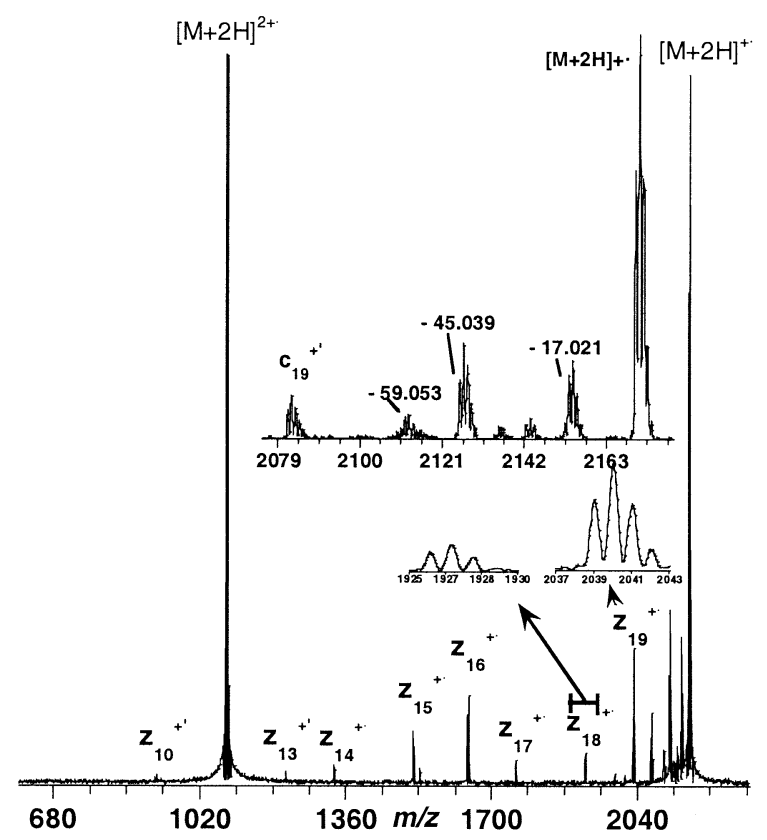

(a)

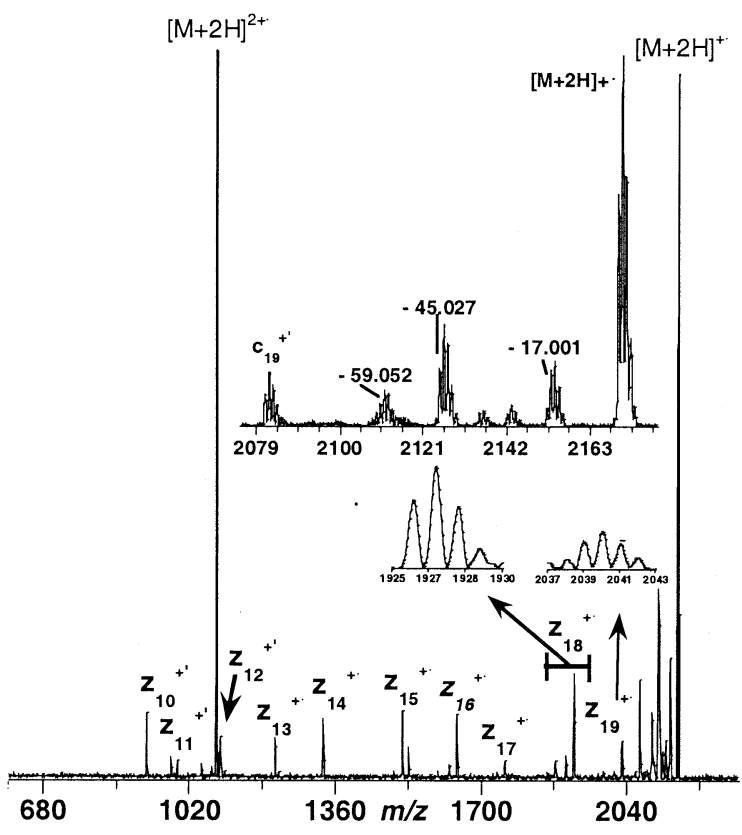

(b)

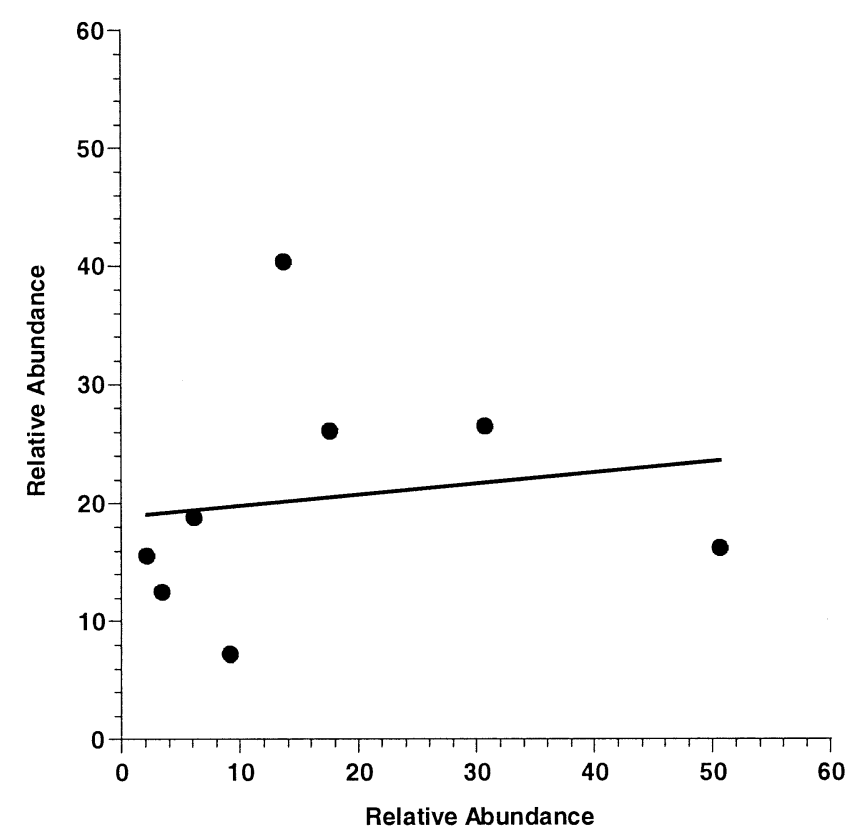

(c)

Figure 4. ECD mass spectra of $2+$ molecular ions of (a) native Trp-cage; (b) D-Tyr substituted Trp-cage. Both spectra were obtained at standard conditions of the ESI interface. The number of data points has been reduced to increase the signal to noise, which affects the resolving power. (c) Correlation plot for the above fragmentation patterns of $z$-ions $(\mathrm{R}=0.15)$.

for both native and D-Tyr forms, which follows from the $3+$ data as well as from the analysis of the $(\mathrm{M} \cdot \mathrm{X})$ regions (Figure $4 a, b)$. Indeed, the pattern of small losses in both spectra is nearly identical, and the losses themselves are consistent with protonation of the arginine, glutamine, asparagine side chains, and the $\mathrm{N}$ terminus [30-32].

In the native form, all backbone carbonyls of the $\mathrm{N}$-terminal part of the Trp-cage except those of $\mathrm{Gln}_{5}$ and $\mathrm{Lys}_{8}$ are involved in neutral hydrogen bonding (Table 1). Protonation of either the N-terminus or glutamine and consecutive charge solvation destabilizes neutral hydrogen bonding near these sites, which results in $z_{19}$ and $z_{15}-z_{16}$ ions (Figure $4 a$ ). Farther away from the protonation sites, the $\mathrm{H}$-bond network remains rather stable, this reflects in the low abundances of $z_{17}-z_{18}$ and $z_{10}-z_{14}$ ions. When the Tyr residue is substituted by the D-isomer, the Tyr side chain no longer 
Table 1. Neutral hydrogen bonding in the native form of Trpcage and the response on D-Tyr substitution of $z$-fragment in ECD of $2+$ ions

\begin{tabular}{llcc}
\hline $\begin{array}{l}\text { Amino } \\
\text { acid }\end{array}$ & $\begin{array}{c}\text { Carbonyl bond } \\
\text { to Amide of }\end{array}$ & $\begin{array}{c}\text { z } \\
\text { Fragment }\end{array}$ & $\begin{array}{c}\text { z Fragment } \\
\text { response } \\
\text { Nat/D-Tyr }\end{array}$ \\
\hline \hline Asn 1 & Gln 5, lle 4 & $\mathrm{z}_{19}$ & $\downarrow \downarrow \downarrow$ \\
Leu 2 & Trp 6 & $\mathrm{z}_{18}$ & $\uparrow \uparrow \uparrow$ \\
Tyr 3 & Leu 7 & $\mathrm{z}_{17}$ & $\leftrightarrow$ \\
Ile 4 & Lys 8 & $\mathrm{z}_{16}$ & $\downarrow$ \\
Gln 5 & none & $\mathrm{z}_{15}$ & $\leftrightarrow$ \\
Trp 6 & Asp 9, Gly 11 & $\mathrm{z}_{14}$ & $\uparrow \uparrow$ \\
Leu 7 & Gly 10 & $\mathrm{z}_{13}$ & $\uparrow \uparrow$ \\
Lys 8 & none & $\mathrm{z}_{12}$ & $\uparrow \uparrow$ \\
Asp 9 & Ser 14 Sidechain & $\mathrm{z}_{11}$ & $\uparrow$ \\
Gly 10 & Ser 13 & $\mathrm{z}_{10}$ & $\uparrow \uparrow \uparrow$ \\
Gly 11 & Ser 14 & na & \\
Pro 12 & Ser 14 & $\mathrm{z}_{8}$ & \\
Ser 13 & none & $\mathrm{z}_{7}$ & \\
Ser 14 & none & $\mathrm{z}_{6}$ & \\
Gly 15 & none & $\mathrm{z}_{5}$ & \\
Arg 16 & Trp 6 Sidechain & na & \\
Pro 17 & none & na & \\
Pro 18 & none & na & \\
Pro 19 & none & $\mathrm{z}_{1}$ & \\
Ser 20 & none & & \\
\hline
\end{tabular}

*Sidechain sidechain interaction between Ser 14 and Asp 9, Arg 16.

acts as the "door-latch" stabilizing the Trp side chain (see Figure 1), and increased mobility of the Trp sidechain is expected upon such substitution. As a result, the H-bond network may destabilize according to the following scenario. The Trp carbonyl weakens its bonding to amides of $\mathrm{Asp}_{9}$ and $\mathrm{Gly}_{11}$ (Table 1), thus increasing the abundance of $z_{14}$ and $z_{11}\left(z_{9}\right.$ is impossible). The reduced bonding of the Trp amide to $\mathrm{Leu}_{2}$ carbonyl leads to increased $z_{18}$. Tyrosine itself, which side chain became much more mobile in the $\mathrm{D}$-form, weakens the interaction of its carbonyl with the amide of $\mathrm{Leu}_{7}$, giving rise to more abundant $z_{13}$. The carbonyl of $\mathrm{Lys}_{8}$, not involved in the H-network, becomes more accessible for charge solvation because of the general loss of rigidity of the Trp-cage structure, thus providing the higher abundance of $z_{12}$. The protons on the Nterminus and $\mathrm{Gln}_{5}$ side chain can now be solvated on a broader range of carbonyls, which reduces the relative abundances of $z_{19}$ and $z_{16}$ ions.

The uncertainty involved in this scenario is not detrimental in the conclusion that neutral tertiary structure is responsible for the observed chiral effects. Generally, multiple-point interactions are necessary to achieve chiral recognition (so called "three-point rule" $[56,57])$. Thus tertiary structure with multiple bonding throughout the molecule (Figure 1 and Table 1) is more likely to be responsible for the obtained high value $R_{\text {chiral }}$ than secondary, ionic-bound structure. This is consistent with the results of Polfer et al., who did extensive force field simulations of secondary structures of decapeptide dications. They found different minimum energy secondary structures for native and
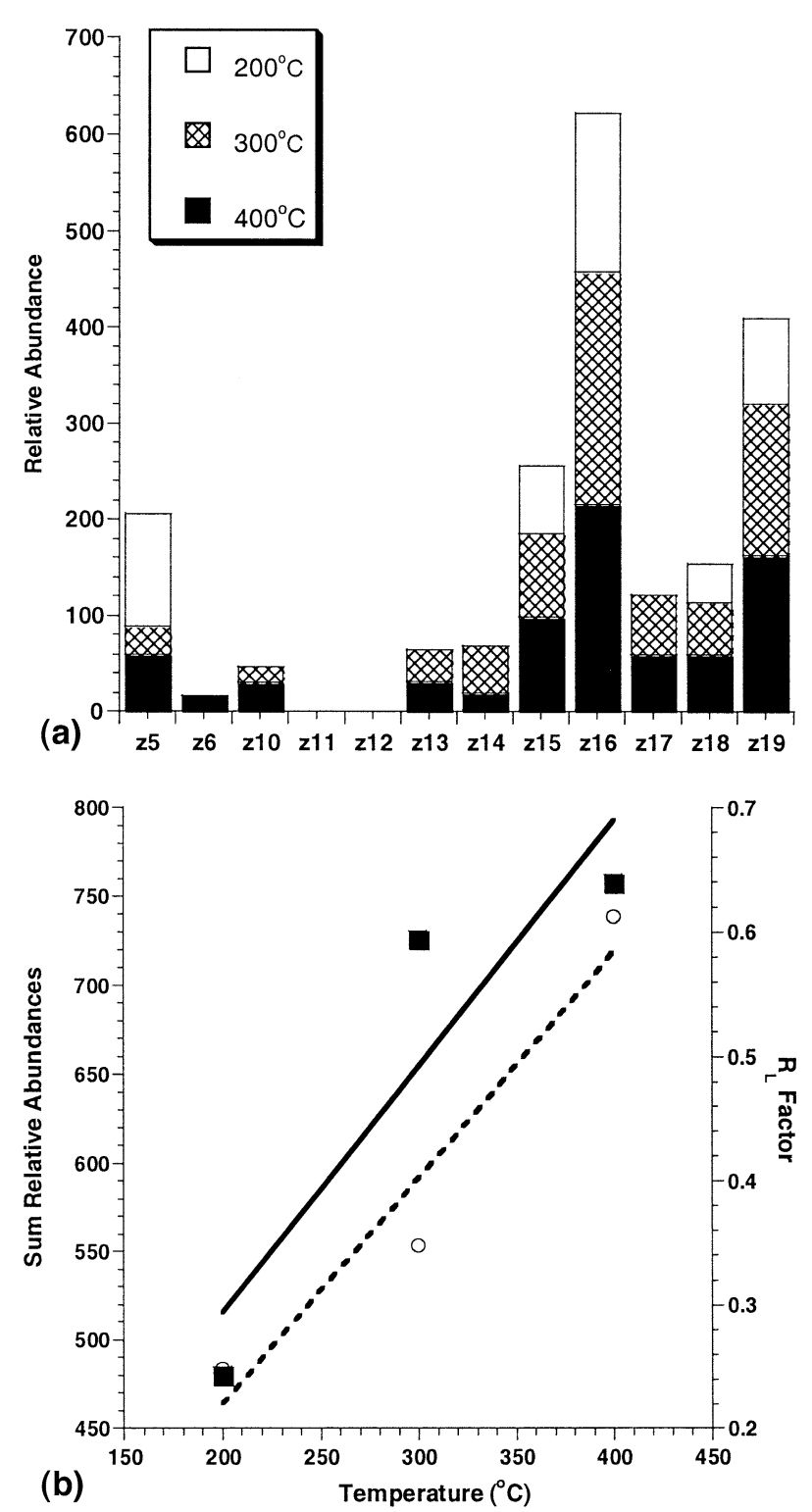

Figure 5. (a) Sum of the relative abundances of $z$-ions in ECD of $2+$ of the native Trp-cage as a function of the drying-gas temperature. (b) Dependence upon the drying-gas temperature of (filled squares) relative abundances of $z$-ions; (open circles) the chiral recognition factor $R_{L}$.

D-Trp substituted LHRH dications, but no significant variation in the frequencies of cleavages of different $\mathrm{N}-\mathrm{C}_{\alpha}$ bonds [53]. It must also be noted that a single D-substitution gave a smaller effect than triple-D substitution (compare Figures $2 \mathrm{~b}$ and $4 \mathrm{~b}$ ). Conversely, the structure that gave the spectrum in Figure 2a must have been least disturbed, with almost intact solution-phase hydrogen bonding.

Additional arguments favoring tertiary structure preservation in the gas phase were obtained when a counterflow of hot drying gas was used to assist the ESI process. This gave new $z$-ions and increased overall $z$-ion abundance in ECD of the native 2+ Trp-cage (Figure 5), but did not alter the pattern of fragmenta- 
tion, which remained distinctly native type $(R=0.80$ and 0.86 for 300 and $400{ }^{\circ} \mathrm{C}$, respectively, compared with $\left.200{ }^{\circ} \mathrm{C}\right)$. The hot gas counterflow heated the spraying capillary and ESI-produced ions during their travel in atmosphere before entering the mass spectrometer. The eventual unfolding of the tertiary structure would not have affected subsequent ionic refolding in the gas phase [26-28] during one-second storage in the accumulating hexapole, should such refolding have taken place. The hexapole is kept at a constant temperature slightly higher than $25^{\circ} \mathrm{C}$, independent of the drying gas temperature; thereby one second should be sufficient folding time at $10^{-4}$ Torr pressure (Trp-cage folds in solution in $\approx 4 \mu \mathrm{s}$, the fastest known folding time [36]). The $60 \%$ increase of $z$-ion abundances with the gas temperature increase from 200 to $400{ }^{\circ} \mathrm{C}$ (Figure $5 b)$ suggest heat-induced partial unfolding during the ionization process [58], specifically before the ions have reached the storage cell where electron capture takes place. At the same time, the $z_{18}$ to $z_{19}$ abundance ratio $R_{L}$ changed from $R_{L}=0.24$ at $200{ }^{\circ} \mathrm{C}$ to $R_{L}=0.61$ at $400{ }^{\circ} \mathrm{C}$, indicating less chiral recognition with a partially unfolded tertiary structure. These results suggest that during ECD, the $2+$ ions did remember their beforevacuum experience, which speaks against ionic refolding and for the preservation of neutral tertiary structure in gas-phase low-charged protein ions. Such an observation has also been made by molecular dynamics simulations. Jarrold explored the gas phase conformations of cytochrome $c$ ions, having shown that $5+$ and even $7+$ ions largely retain the simulated crystal structure in the gas phase [59].

The picture changes when charging increases, and in our interpretation the dominance of ionic bonding becomes prevalent. ECD of 3+ Trp-cage (Figure 6) showed extensive, but very similar fragmentation for both stereoisomers. Correlation analysis of the $3+$ data confirmed a significant resemblance in the patterns, yielding $\mathrm{R}=0.90$ for $z$-ions and $\mathrm{R}=0.94$ for $c$-ions (Figure 6c). Even abundances of $z_{18}$ and $z_{19}$ ions became more similar, yielding $R_{L}=0.65 \pm 0.06$ for the native form and $R_{D}=0.99 \pm 0.07$ for the $\mathrm{D}$-Tyr form. The degree of chiral distinction in $3+$ was thus $R_{\text {chiral }}=1.52$ \pm 0.09 , measurable but significantly smaller than in $2+$ ions. To understand the role of ionic bonding and its effects on ECD fragmentation, molecular dynamics calculations may be insightful. These calculations should however be performed on a higher level than currently practical, as follows from the inconclusive results obtained by Polfer et al. in trying to relate ECD fragmentation to the probability of charge solvation of backbone carbonyls.

Generally, ECD spectra of $n+$ ions can pinpoint $(n-$ $1)+$ protonation sites by the charge state shift in the ECD fragments. For instance, McLafferty et al. could locate positions of 12 protons in 13+ of ubiquitin [28]. The position of the $n$-th protonation site usually remains obscure, the reason being this site is the least basic and has the highest probability of being neutral- ized [48], preserving charges on the other $(n-1)+$ sites but erasing information of its own location. Indeed, the recombination energy at a particular site can be estimated as $\mathrm{RE} \approx 14.2 \mathrm{eV}-\mathrm{PA}$, where PA is the proton affinity (including coulombic effects) of that site [49]. When ECD fragments separate following the $n$-th charge neutralization and bond cleavage, the remaining protons leave the carbonyls on which they are solvated and stay on the more basic $(n-1)$ protonation sites. Thus a protonation site mapping is usually obtained for these protons, despite the gas-phase presence of protein ions of ionic-bound secondary and higher order structure. Since in $(n-1)+$ molecular ions this $n$-th site is not protonated due to its lower basicity, the $(n-1)+$ protonation sites revealed by ECD of $n+$ ions are the ones protonated in $(n-1)+$ molecular ions.

The ECD of 3+ Trp-cage highlighted the protonation sites in $2+$ ions. Figure 7 demonstrates the shifts in the charge states of $c$ - and $z$-fragments in the ECD spectra of native $3+$ (D-Tyr data were almost identical), which occurred after Gln ${ }_{5}$ and $\operatorname{Arg}_{16}$. All fragments except $z_{16}$ appear in just one charge state, which means that two protons are located on side chains of $\mathrm{Gln}_{5}$ and $\operatorname{Arg}_{16}$ and there is no location distribution in $3+$ ions for these two protons. The surprising absence of protonation at the lysine residue, no shift in the charge state of residues before or after, is presumably because its side chain cannot effectively solvate the proton on a backbone carbonyl. Without solvation the basicity of the lysine residue is reduced [60]. Coulombic repulsion (Lys 8 is closer to the protonated $\mathrm{Arg}_{16}$ than $\mathrm{Gln}_{5}$ ) also contributes to the gas phase basicity. At the same time, Gln is the most basic residue after Arg, His and Lys [61] and it seems to find multiple solvation opportunities. This follows from the presence of $z_{16}$ (Ile $_{4}-\mathrm{G} \ln _{5}$ cleavage) in two charge states, leading to a fractional average charge for this fragment. We are offering the following interpretation for the $z_{16}$ results. The third proton is located at the N-terminus and is shared between the $\mathrm{N}$-terminal amine and the asparagine side chain. Coulombic repulsion between the charges separated by just three residues forces Gln side chain to be solvated on the right-hand side of the sequence, while the $\mathrm{N}$ terminal proton can be shared with the preceding (belonging to $\mathrm{Ile}_{4}$ ) carbonyl. Neutralization of this proton leads to $z_{16}^{2+\cdot}$ ion. Additionally, when the protonated Gln side chain is solvated on $\mathrm{Ile}_{4}$ carbonyl the solvation energy is reduced because of the tension in the bent chain and the coulombic repulsion with the nearby third charge (the coulombic energy at such distance exceeds $1 \mathrm{eV}$ ). Thus the recombination energy for neutralization of this configuration is increased compared to Gln side-chain solvation elsewhere, and neutralization occurring with an increased probability leads to a $z_{16}^{+\cdot}$ ion and the complementary $c_{4}^{+^{\prime}}$ fragment. The latter acquires high kinetic energy because of the mass difference with $z_{16}$ and energetic recombination, and its ion cloud loses coherence thus being poorly detected in FTMS. 


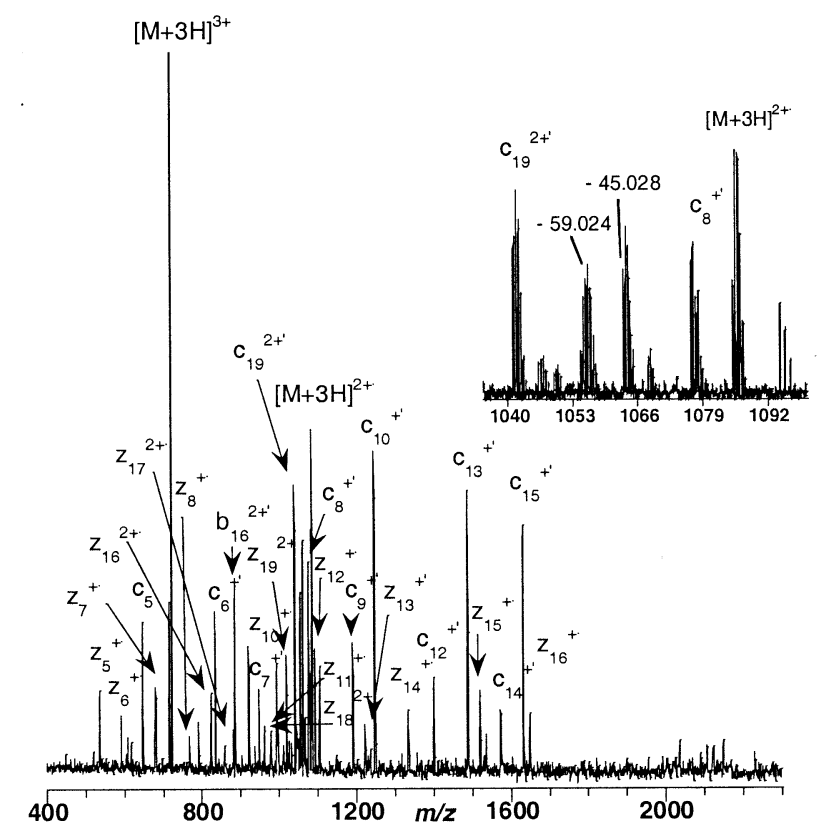

(a)

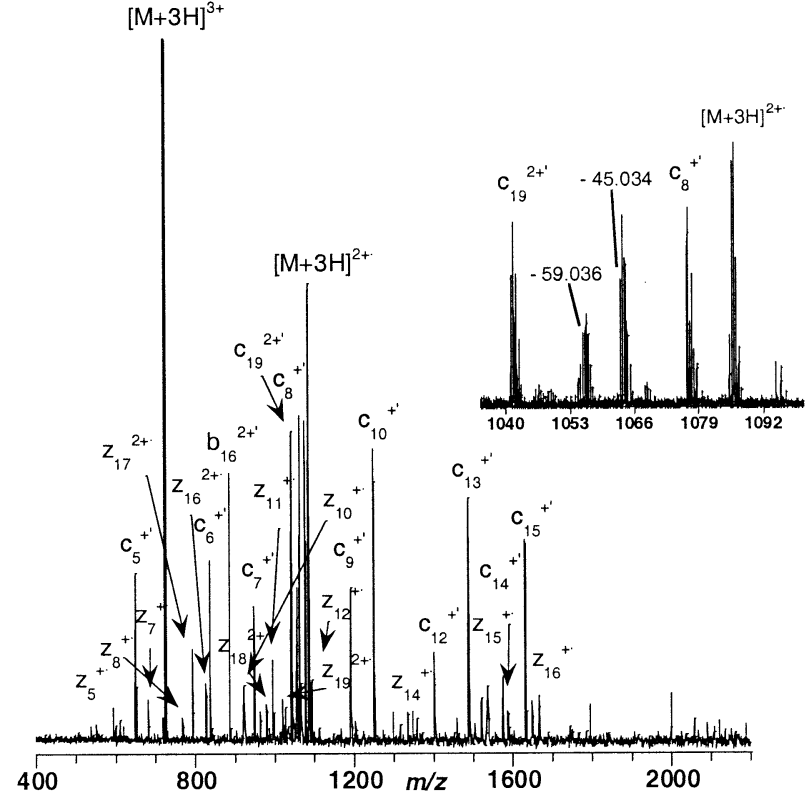

(b)

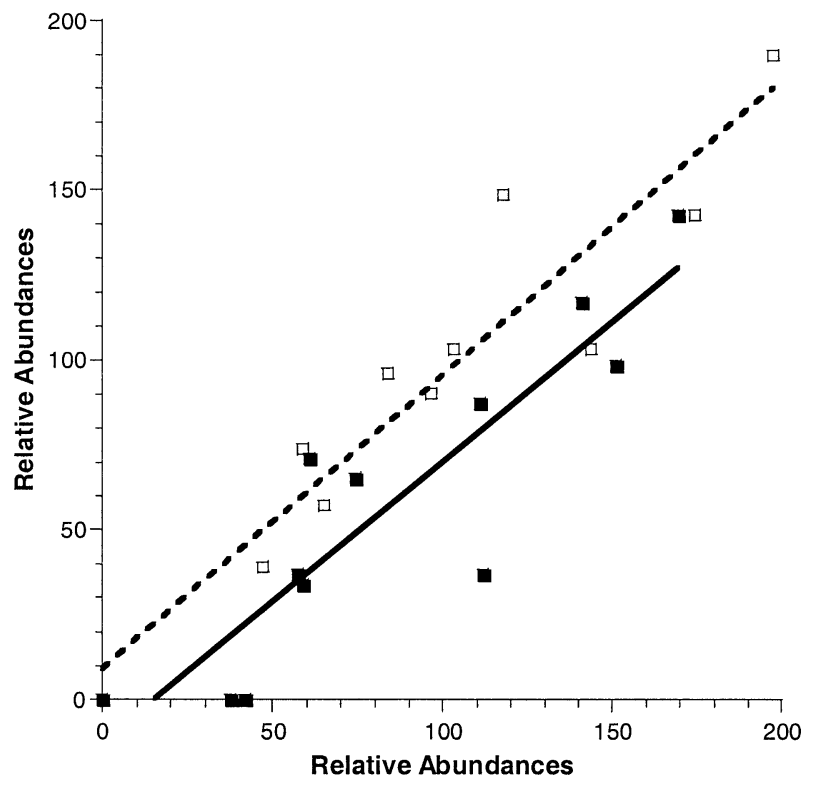

(c)

Figure 6. ECD mass spectra of $3+$ molecular ions of (a) native Trp-cage; (b) D-Tyr substituted Trp-cage. (c) Correlations between the two fragmentation patterns: (filled squares) for $z$-ions, $R=0.90$ (open squares) for $c$-ions, $\mathrm{R}=0.94$.

In agreement with that scenario, trace amounts of the complementary $c_{4}^{+{ }^{\prime}}$ ions are detected in the ECD spectrum (data are not included in Figure 7). The increased abundance of $z_{16}^{+\cdot}$ ion in the 2+ ECD spectrum of native Trp-cage (vide supra) agrees well with the implied solvation of the $\mathrm{Gln}_{5}$ side chain on the $\mathrm{Ile}_{4}$ carbonyl. Apparently, the N-terminal proton can also be solvated on the $\mathrm{Pro}_{19}$ carbonyl that is free from neutral hydrogen bonding (Table 1; $\mathrm{Asn}_{1}$ side chain is close to the C-terminus, see Figure 1 left). Neutralization of this proton in $2+$ and $3+$ ions leads to $c_{19}$ fragments (inserts in Figures 2, 4, and 6). The higher probability of protonation of the $\mathrm{N}$-terminus in $3+$ ions compared to $2+$ ions leads to the high abundances of $c_{19}$ fragments in the corresponding ECD mass spectra.

The $(\mathrm{M} \cdot \mathrm{X})$ patterns of both charge states are similar (compare the inserts in Figures 4 and 6), which is consistent with protonation of both $\mathrm{Gln}_{5}$ and $\operatorname{Arg}_{16}$ in $2+$ and $3+$ species. Close examination shows losses of 45 , and 59 Da which have been attributed to the side 


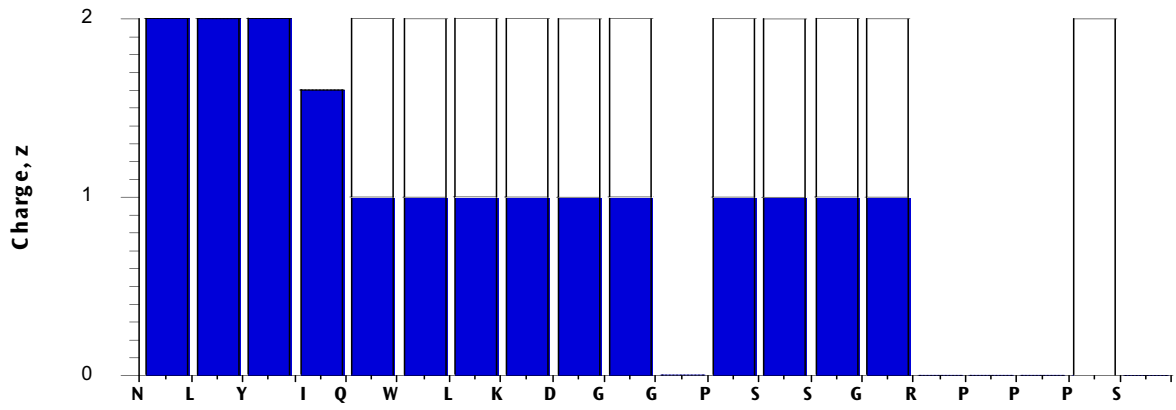

Residue

Figure 7. Distribution of average charge states of ECD fragments of $3+$ of native Trp-cage: open columns-c-ions; filled columns-z-ions. Note the shifts in the charge state after $Q\left(G n_{5}\right)$ and $R$ $\left(\operatorname{Arg}_{16}\right)$ that singles them out as protonation sites.

chain losses of asparagine/glutamine (45.022 and 59.037) and arginine (59.048) [31-33]. The doublets in the isotopic distribution of the -59 Da peak are not easily resolved and it is likely that side chain losses from both the arginine and asparagine/glutamine are present. The measured accurate mass of the $-59 \mathrm{Da}$ peak is consistent with the dominance of the Arg losses for $2+$ ions, while for $3+$ species it is closer to those from Asn/Gln. This is consistent with protonation suggested for these residues.

\section{Conclusions and Outlook}

Continuing exploration of the ECD technique predicted by Fred McLaffery [62] and developed originally in his lab [63] demonstrated the sensitivity of ECD fragmentation pattern to differences in gas-phase tertiary protein structure imposed by a single D-amino acid substitution. This sensitivity manifests itself for the lowest charge state, and affords excellent chiral recognition. All experimental evidence supports the mechanism of the chiral recognition acting through the neutral hydrogen bonding (tertiary structure) largely preserved from the solution phase in the low-charged protein. The chiral effect is diminished at higher temperature when the tertiary structure is degraded, and it is greatly reduced for higher charge states where ionic interactions largely destroy it.

Not unexpectedly, fragmentation patterns from vibrational activation did not provide stereoisomer differentiation even for the lowest charge state, underlying the special position occupied by ECD among other MS/MS fragmentation techniques. At the same time, vibrational activation seems to be able to probe the gas-phase stabilities of native versus D-substituted structures. Consistent with the lower stability of the D-Tyr stereoisomer, proton NMR for this molecule showed the absence, in solution, of characteristic native structure even at $5{ }^{\circ} \mathrm{C}[64]$.

The results of the current study encourage continuing research in this area. Quantitative measurements of the D-Tyr content in a mixture of all-L and D-Tyr forms will be attempted. Systematic single and multiple Dsubstitution in Trp-cage and other proteins will be performed with the aim to determine the relative importance of each substitution in defining the tertiary structure. This structure will be probed by ECD of $2+$ ions, and its stability by CAD or IRMPD. The ECD mass spectra need to be correlated with the NMR solution data. The general approach for charge localization in $n+$ ions by analysis of ECD of their $(n+1)+$ ions will be further tested on different polypeptides.

\section{Acknowledgments}

This article is dedicated to Dr. Fred W. McLafferty.

Some of the Trp-cage stereoisomers used in this work were synthesized and purified by Å. Engström. P. Håkansson is in charge of the Uppsala FTICR MS instrument. This work was supported by the Danish Research Council (grant SNF 51-000358), INTAS grant 99-0478, Wallenberg Consortium North (grant WCN2003-UU/SLU-009) as well as Swedish research council (grant 621-2002-5025). The authors acknowledge Nick Polfer and Pat Langridge-Smith for insightful discusion.

\section{References}

1. Fenn, J. B.; Mann, M.; Chin Kai Meng, S. F. W.; Whitehouse, C. M. Electrospray Ionization for Mass Spectrometry of Large Biomolecules. Science 1989, 246, 64-71.

2. Eigen, M.; de Maeyer, L. Relaxation Methods; Interscience: New York, NY, 1963; pp 895-1054.

3. Oneil, K. T.; Degrado, W. F. A Thermodynamic Scale for the Helix-Forming Tendencies of the Commonly Occurring Amino-Acids. Science 1990, 250, 646-651.

4. Pace, C. N.; Shirley, B. A.; McNutt, M.; Gajiwala, K. Forces Contributing to the Conformational Stability of Proteins. Faseb J. 1996, 10, 75-83.

5. Sturtevant, J. M. The Thermodynamic Effects of Protein Mutations. Curr. Opin. Struct. Biol. 1994, 4, 69-78.

6. Kaltashov, I. A.; Eyles, S. J. Studies of Biomolecular Conformations and Conformational Dynamics by Mass Spectrometry. Mass Spectrom. Rev. 2002, 21, 37-71.

7. Lorenz, S. A.; Maziarz, E. P.; Wood, T. D. Electrospray Ionization Fourier Transform Mass Spectrometry of Macromolecules: The First Decade. Appl. Spectroscop. 1999, 53, 18A36A. 
8. Smith, R. D.; Loo, J. A.; Loo, R. R. O.; Busman, M.; Udseth, H. R. Principles and Practice of Electrospray Ionization-MassSpectrometry for Large Polypeptides and Proteins. Mass Spectrom. Rev. 1991, 10, 359-451.

9. Pramanik, B. N.; Bartner, P. L.; Mirza, U. A.; Liu, Y.; Ganguly, A. K. Electrospray Ionization Mass Spectrometry for the Study of Non-Covalent Complexes: An Emerging Technology. J. Mass Spectrom. 1998, 33, 911-920.

10. Loo, J. A. Electrospray Ionization Mass Spectrometry: A Technology for Studying Noncovalent Macromolecular Complexes. Int. J. Mass Spectrom. 2000, 200, 175-186.

11. Miranker, A. D. Protein Complexes and Analysis of Their Assembly by Mass Spectrometry. Curr. Opin. Struct. Biol. 2000, 10, 601-606.

12. Sobott, F. Protein Complexes Gain Momentum. Curr. Opin. Struct. Biol. 2002, 12, 729-734.

13. Jurchen, J. C.; Williams, E. R. Origin of Asymmetric Charge Partitioning in the Dissociation of Gas-phase Protein Homodimers. J. Am. Chem. Soc. 2003, 125, 2817-2826.

14. McLafferty, F. W.; Guan, Z. Q.; Haupts, U.; Wood, T. D.; Kelleher, N. L. Gaseous Conformational Structures of Cytochrome. C. J Am. Chem. Soc. 1998, 120, 4732-4740.

15. Wood, T. D.; Chorush, R. A.; Wampler, F. M. III.; Little, D. P.; O'Connor, P. B.; McLafferty, F. W. Gas-Phase Folding and Unfolding of CytochromeC Cations. Proc. Natl. Acad. Sci. U.S.A. 1995, 92, 2451-2454.

16. Lorenz, S. A.; Maziarz, E. P.; Woods, T. D. Using Solution Phase Hydrogen/Deuterium (H/D) Exchange to Determine the Origin of Non-Covalent Complexes Observed by Electrospray Ionization Mass Spectrometry: In Solution or in Vacuo? J. Am. Soc. Mass Spectrom. 2001, 12, 795-804.

17. Wang, F.; Freitas, M. A.; Marshall, A. G.; Sykes, B. D. GasPhase Memory of Solution-phase Protein Conformation: H/D Exchange and Fourier Transform Ion Cyclotron Resonance Mass Spectrometry of the N-terminal Domain of Cardiac Troponin. C. Int. J. Mass Spectrom. 1999, 192, 319-325.

18. Green, M. K.; Lebrilla, C. B. Ion-Molecule Reactions as Probes of Gas-phase Structures of Peptides and Proteins. Mass Spectrom. Rev. 1997, 16, 53-71.

19. Loo, R. R. O.; Smith, R. D. Investigation of the Gas-Phase Structure of Electrosprayed Proteins Using Ion-Molecule Reactions. J. Am. Soc. Mass Spectrom. 1994, 5, 207-220.

20. Iavarone, A. T.; Williams, E. R. Collisionally Activated Dissociation of Supercharged Proteins Formed by Electrospray Ionization. Anal. Chem. 2003, 75, 4525-4533.

21. Laskin, J.; Futrell, J. H. Collisional Activation of Peptide Ions in FT-ICR Mass Spectrometry. Mass Spectrom. Rev. 2003, 22, 158-181.

22. Dufresne, C. P.; Wood, T. D.; Hendrickson, C. L. HighResolution Electrospray Ionization Fourier Transform Mass Spectrometry with Infrared Multiphoton Dissociation of Glucokinase from. Bacillus stearothermophilus. J. Am. Soc. Mass Spectrom. 1998, 9, 1222-1225.

23. Charlebois, J. P.; Patrie, S. M.; Kelleher, N. L. Electron Capture Dissociation and C-13, N-15 Depletion for Deuterium Localization in Intact Proteins After Solution-Phase Exchange. Anal. Chem. 2003, 75, 3263-3266.

24. Kjeldsen, F.; Haselmann, K. F.; Sorensen, E. S.; Zubarev, R. A. Distinguishing of Ile/Leu Amino Acid Residues in the PP3 Protein by (Hot) Electron Capture Dissociation in Fourier Transform Ion Cyclotron Resonance Mass Spectrometry. Anal. Chem. 2003, 75, 1267-1274.

25. Szilagyi, Z.; Drahos, L.; Vekey, K. Conformation of Doubly Protonated Peptides Studied by Charge-Separation Reactions in Mass Spectrometry. J. Mass Spectrom. 1997, 32, 689-696.

26. Haselmann, K. F.; Jorgensen, T. J. D.; Budnik, B. A.; Jensen, F.; Zubarev, R. A. Electron Capture Dissociation of Weakly
Bound Polypeptide Polycationic Complexes. Rapid Commun. Mass Spectrom. 2002, 16, 2260-2265.

27. Oh, H.; Breuker, K.; Sze, S. K.; Ge, Y.; Carpenter, B. K.; McLafferty, F. W. Secondary and Tertiary Structures of Gaseous Protein Ions Characterized by Electron Capture Dissociation Mass Spectrometry and Photofragment Spectroscopy. Proc. Natl. Acad. Sci. U.S.A. 2002, 99, 15863-15868.

28. Breuker, K.; Oh, H. B.; Horn, D. M.; Cerda, B. A.; McLafferty, F. W. Detailed Unfolding and Folding of Gaseous Ubiquitin Ions Characterized by Electron Capture Dissociation. J. Am. Chem. Soc. 2002, 124, 6407-6420.

29. Horn, D. M.; Breuker, K.; Frank, A. J.; McLafferty, F. W. Kinetic Intermediates in the Folding of Gaseous Protein Ions Characterized by Electron Capture Dissociation Mass Spectrometry. J. Am. Chem. Soc. 2001, 123, 9792-9799.

30. Budnik, B. A.; Nielsen, M. L.; Olsen, J. V.; Haselmann, K. F.; Horth, P.; Haehnel, W.; Zubarev, R. A. Can Relative Cleavage Frequencies in Peptides Provide Additional Sequence Information? Int. J. Mass Spectrom. 2002, 219, 283-294.

31. Cooper, H. J.; Hudgins, R. R.; Håkansson, K.; Marshall, A. G. Characterization of Amino Acid Side Chain Losses in Electron Capture Dissociation. J. Am. Soc. Mass Spectrom. 2002; 13, 241-249.

32. Haselmann, K. F.; Budnik, B. A.; Kjeldsen, F.; Polfer, N. C.; Zubarev, R. A. Can the $(-\mathrm{X})$ Region in Electron Capture Dissociation Provide Reliable Information on Amino Acid Composition of Polypeptides? Eur. J. Mass Spectrom. 2002, 8, 461-469.

33. Cooper, H. J.; Håkansson, K.; Marshall, A. G.; Hudgins, R. R.; Haselmann, K. F.; Kjeldsen, F.; Budnik, B. A.; Polfer, N. C.; Zubarev, R. A. The Diagnostic Value of Amino Acid SideChain Losses in Electron Capture Dissociation of Polyepeptides. Comment on: "Can the (Mo-X) Region in Electron Capture Dissociation Provide Reliable Information on Amino Acid Composition of Polypeptides?" Eur. J. Mass Spectrom. 2003, 9, 221-222.

34. Meot-Ner, M. The Ionic Hydrogen Bond. 2. Intramolecular and Partial Bonds. Protonation of Polyethers, Crown Ethers, and Diketones. J. Am. Chem. Soc. 1983, 105, 4906-4911.

35. Neidigh, J. W.; Fesinmeyer, R. M.; Andersen, N. H. Designing a 20-Residue Protein. Nat. Struct. Biol. 2002, 9, 425-430.

36. Snow, C. D.; Zagrovic, B.; Pande, V. S. The Trp Cage: Folding Kinetics and Unfolded State Topology via Molecular Dynamics Simulations. J. Am. Chem. Soc. 2002, 124, 14548-14549.

37. Qiu, L. L.; Pabit, S. A.; Roitberg, A. E.; Hagen, S. J. Smaller and Faster: The 20-Residue Trp-cage Protein Folds in $4 \mathrm{mu}$ s. J. Am. Chem. Soc. 2002, 124, 12952-12953.

38. Chowdhury, S.; Lee, M. C.; Xiong, G. M.; Duan, Y. Ab Initio Folding Simulation of the Trp-cage Mini-Protein Approaches NMR Resolution. J. Mol. Biol. 2003, 327, 711-717.

39. Carnevali, P.; To'th, G.; Toubassi, G.; Meshkat S. N. Fast Protein Structure Prediction Using Monte Carlo Simulations with Modal Moves. J. Am. Chem. Soc. 2003, 125, 14244-14245.

40. Schug, A. H. T.; Wenzel, W. Reproducible Protein Folding with the Stochastic Tunneling Method. Phys. Rev. Lett. 2003, 91, Art. No. 158102.

41. Barua, B.; Andersen, N. H. Determinants of Miniprotein Stability: Can Anything Replace a Buried H-Bonded Trp Sidechain? Lett. Pept. Sci. 2001, 8, 221-226.

42. Krause, E.; Beyermann, M.; Dathe, M.; Rothemund, S.; Bienert, M. Location of an Amphipathic $\alpha$-Helix in Peptides Using Reversed-Phase HPLC Retention Behavior of D-Amino-Acid Analogs. Anal. Chem. 1995, 67, 252-258.

43. Mitchell, J. B. D-Amino Acid Residues in Peptides and Proteins. Proteins: Structure, Function, and Genomics. 2003, 50, 563-571. 
44. Haselmann, K. F.; Budnik, B. A.; Olsen, J. V.; Nielsen, M. L.; Reis, C. A.; Clausen, H.; Johnsen, A. H.; Zubarev, R. A. Advantages of External Accumulation for Electron Capture Dissociation in Fourier Transform Mass Spectrometry. Anal. Chem. 2001, 73, 2998-3005.

45. Tsybin, Y. O.; Hakansson, P.; Budnik, B. A.; Haselmann, K. F.; Kjeldsen, F.; Gorshkov, M.; Zubarev, R. A. Improved LowEnergy Electron Injection Systems for High Rate Electron Capture Dissociation in Fourier Transform Ion Cyclotron Resonance Mass Spectrometry. Rapid Commun. Mass Spectrom. 2001, 15, 1849-1854.

46. Boeckmann, B.; Bairoch, A.; Apweiler, R.; Blatter, M. C.; Estreicher, A.; Gasteiger, E.; Martin, M. J.; Michoud, K.; O'Donovan, C.; Phan, I.; Pilbout, S.; Schneider, M. The SWISSPROT Protein Knowledgebase and Its Supplement TrEMBL in 2003. Nucl. Acids Res. 2003, 31, 365-370.

47. Humphrey, W.; Dalke, A.; Schulten, K. VMD: Visual Molecular Dynamics. J. Mol. Graphics 1996, 14, 33.

48. Williams, E. R. Proton Transfer Reactivity of Large Multiply Charged Ions. J. Mass Spectrom. 1996, 31, 831-842.

49. Zubarev, R. A.; Haselmann, K. F.; Budnik, B.; Kjeldsen, F.; Jensen, F. Towards an Understanding of the Mechanism of Electron-capture Dissociation: A Historical Perspective and Modern Ideas. Eur. J. Mass Spectrom. 2002, 8, 337-349.

50. Tsaprailis, G.; Nair, H.; Somogyi, A.; Wysocki, V. H.; Zhong, W. Q.; Futrell, J. H.; Summerfield, S. G.; Gaskell, S. J. Influence of Secondary Structure on the Fragmentation of Protonated Peptides. J. Am. Chem. Soc. 1999, 121, 5142-5154.

51. Kjeldsen, F.; Haselmann, K. F.; Budnik, B. A.; Jensen, F.; Zubarev, R. A. Dissociative Capture of Hot (3-13 eV) Electrons by Polypeptide Polycations: An Efficient Process Accompanied by Secondary Fragmentation. Chem. Phys. Lett. 2002, 356, 201-206.

52. Kjelden, F.; Zubarev, R. A. Secondary Losses via ?-Lactam Formation in Hot Electron Capture Dissociation: A Missing Link to Complete de Novo Sequencing of Proteins? J. Am. Chem. Soc. 2003, 125, 6628-6629.

53. Polfer, N. C. Structural Elucidation of Peptides and Proteins by Fourier Transform Ion Cyclotron Resonance Mass Spectrometry;
Thesis, University of Edinburgh: Edinburgh, UK, 2003, 95-226.

54. Wu, L. M.; Cooks, R. G. Chiral Analysis Using the Kinetic Method with Optimized Fixed Ligands: Applications to Some Antibiotics. Anal. Chem. 2003, 75, 678-684.

55. Wu, C.; Siems, W. F.; Klasmeier, J.; Hill, H. H. Separation of Isomeric Peptides Using Electrospray Ionization/High-Resolution Ion Mobility Spectrometry. Anal. Chem. 2000, 72, 391395.

56. Tao, W. A.; Zhang, D. X.; Nikolaev, E. N.; Cooks, R. G. Copper(II)-Assisted Enantiomeric Analysis of D,L-Amino acids Using the Kinetic Method: Chiral Recognition and Quantification in the Gas Phase. J. Am. Chem. Soc. 2000, 122, 10598-10609.

57. Salem, L. C. X; Segal, G.; Hiberty, . C.; Minot, C.; Leforestier, C.; Sautet, P. Chirality Forces. J. Am. Soc. Mass Spectrom. 1987, 109, 2887-2894.

58. Handman, M.; Curcuruto, O. Probing Conformational Changes in Some Proteins by Positive-Ion Electrospray Mass Spectrometry. Rapid Commun. Mass Spectrom. 1994, 8 , 144-147.

59. Jarrold, M. Unfolding, Refolding, and Hydration of Proteins in the Gas Phase. Acc. Chem. Res. 1999, 32, 360-367.

60. Schnier, P. D.; Gross, D. S.; Williams, E. R. Electrostatic Forces and Dielectric Polarizability of Multiply Protonated Gas-Phase Cytochrome-C Ions Probed by Ion/Molecule Chemistry. J. Am. Chem. Soc. 1995, 117, 6747-6757.

61. Wu, Z.; Fenselau, C. Proton Affinity of Arginine Measured by the Kinetic Approach. Rapid Commun. Mass Spectrom. 1992, 6, 403-405.

62. McLafferty, F. W. Tandem Mass Spectrometry of Large Molecules. Mass Spectrometry in the Analysis of Large Molecules, C. J. McNeal, ed.; J. Wiley: New York, 1986, pp 107-120.

63. Zubarev, R. A.; Kelleher, N. L.; McLafferty, F. W. Electron Capture Dissociation of Multiply Charged Protein Cations. A Nonergodic Process. J. Am. Chem. Soc. 1998, 120, 3265-3266.

64. Adams, C. M.; Orekhov, V.; Zubarev, R. A., unpublished NMR data. 